\title{
$\begin{array}{r}\text { WAGENINGEN } \\ \hline\end{array}$
}

\author{
Moisture Dependent Diffusion and Shrinkage in Yam during Drying. \\ Amankwah, E. A., Dzisi, K. A., van Straten, G., \& van Boxtel, A. J. B.
}

This is a "Post-Print" accepted manuscript, which has been Published in "International Journal of Food Engineering"

This version is distributed under a non-commercial no derivatives Creative Commons (c) (1) $\circledast \Theta$

(CC-BY-NC-ND) user license, which permits use, distribution, and reproduction in any medium, provided the original work is properly cited and not used for commercial purposes. Further, the restriction applies that if you remix, transform, or build upon the material, you may not distribute the modified material.

Please cite this publication as follows:

Amankwah, E. A., Dzisi, K. A., van Straten, G., \& van Boxtel, A. J. B. (2018). Moisture Dependent Diffusion and Shrinkage in Yam during Drying. International Journal of Food Engineering, 14(7-8). https://doi.org/10.1515/ijfe-2017-0394

You can download the published version at:

https://doi.org/10.1515/ijfe-2017-0394 


\section{Moisture dependent diffusion and shrinkage in yam during drying}

\author{
E.A. Aamankwah ${ }^{1,2}$, K.A. Dsizi ${ }^{2}$, G. van $\operatorname{Straten}^{1}$, A.J.B. van Boxtel ${ }^{1}$
}

${ }^{1}$ Biobased Chemistry and Technology, Wageningen University Research. POBox 17, 6700 AA, Wageningen, the Netherlands

${ }^{2}$ Food Science and Technology and Biochemistry and Biotechnology Departments, Kwame Nkrumah University of Science and Technology, Kumasi, Ghana

\section{Abstract}

Crank's analytical approximations for Fick's diffusion equation were used to investigate the effect of moisture dependent sample thickness and diffusivity on the drying behavior of yam (Dioscoreaceae rotundata) cubicles. Drying and shrinkage experiments were separately conducted at temperatures of 30,40 and $50^{\circ} \mathrm{C}$ in a cabinet drier. The comparative study of moisture dependent shrinkage and moisture dependent diffusivity justifies the interdependence of diffusivity and shrinkage due to water loss during drying. The behavior for yam is best explained by a combination of fractal moisture dependent shrinkage and moisture dependent diffusion, describing both the drying and rate curves better with good prediction of the high moisture regions. This assertion was reached as a result of low mean square error, standard error, percentage relative deviation, Akaike's Information Criterion and high coefficient of determination. The results may indicate a varying mobility of water in food matrix of different moisture content in the multilayer and monolayer regimes.

Keywords: Yam (Dioscoreaceae rotundata), drying curves, water transport, effective diffusion 


\section{Introduction}

27 Yam, a delicacy and a major source of food supply for many African, Asian and Latin American 28 countries, has a moisture content of about $70 \%$ when harvested, which make yam perishable [1]

29 This can be prevented by drying into powders and storage under appropriate conditions. The 30 powders are incorporated into soups, baby foods or processed into a thick viscous diet called

31 Amala in Nigeria or Fufu in Ghana. Yam powder is obtained from yam cubicles which are dried

32 in a traditional way like open sun drying or by using industrial or solar dryers. During drying,

33 shrinkage occurs. To advance drying technology, it is essential to quantify and analyze the drying 34 characteristics of yam cubicles, not neglecting the shrinkage factor.

Torres et al. [2] report about the drying characteristics of two yam species (Dioscoreaceae alata) by using a classical model approach. The use of the Page equation is a semi-empirical

37 approach and does not reflect the diffusion behavior that occurs in many food products as formulated by $[3,4,5]$ who have shown a linear relationship between moisture and shrinkage. Sjöholm and Gekas [6] have shown a linear relationship between $D_{\text {eff }}$ and moisture content during apple drying as a consequence of volume change with moisture content. The change of moisture

41 content in these products is given by Fick's second law:

$$
\frac{d X(t, x)}{d t}=\frac{d}{d x} D \frac{d X(t, x)}{d x}
$$

42 with $X(t, x)$ the moisture content (kg water/kg solids) as a function of time $(t)$ and position $(x)$ in 43 the product compared to the center. $D$ is the effective diffusion coefficient $\left(\mathrm{m}^{2} / \mathrm{s}\right)$. 
46 resistance and time invariant diffusion coefficient the analytical solutions for the average moisture

47 content in an infinite sized slab is given as:

$$
M R(t)=\frac{X(t)-X_{e}}{X_{o}-X_{e}}=\frac{8}{\pi^{2}} \sum_{n=0}^{\infty} \frac{1}{(2 n+1)^{2}} \exp \left(-\frac{(2 n+1)^{2} \pi^{2} D}{L^{2}} t\right)
$$

48 With $M R(t)$ the moisture ratio, $X(t)$ the actual averaged moisture content, $X_{0}$ the initial moisture 49 content, $X_{e}$ the equilibrium moisture content at the end of drying, all in $\mathrm{kg} \mathrm{water} / \mathrm{kg}$ solids and $50 L(m)$ the thickness of the slab.

51 Equation 2 represents a series of terms and writing the first 3 terms out $(n=0,1$ and 2$)$ gives

$$
M R(t)=\frac{8}{\pi^{2}} \exp \left(-\frac{\pi^{2} D}{L^{2}} t\right)+\frac{8}{9 \pi^{2}} \exp \left(-\frac{9 \pi^{2} D}{L^{2}} t\right)+\frac{8}{25 \pi^{2}} \exp \left(-\frac{25 \pi^{2} D}{L^{2}} t\right)+.
$$

52 The time scales of the successive terms differ strongly, i.e. the time scale of the third term is very

53 short, for the second term, longer but still fast and the expression is dominated by the time scale 54 of the first term. Together with a decreasing pre-exponential factor for each term, in practice just 55 one or two terms suffice ( $n=0$ and 1), leading to Eq. 4 as a suitable basis for the interpretation 56 of drying curves $(n=0$ and 1$)$.

$$
M R(t)=\frac{8}{\pi^{2}} \exp \left(-\frac{\pi^{2} D}{L^{2}} t\right)+\frac{8}{9 \pi^{2}} \exp \left(-\frac{9 \pi^{2} D}{L^{2}} t\right)
$$

57 Often only one term is used as reported by $[8,9,10,11,5]$.

58 In our experiments on drying of yam cubicles with a limited size, we observed systematic 59 deviations between the data and fitted curves based on Eq. 4. Assuming that moisture transport for 
60 yam is diffusion limited, these deviations can be a result of the following issues: (i) the geometry

61 of the cubicles does not satisfy the conditions for infinite sized slabs, (ii) moisture transport is

62 affected by shrinkage [12], or (iii) the effective diffusion coefficient is not constant [13].

64

65

66

67

68

69

70

71

72

73

74

75

76

\section{7}

78

79

80

In this work we perform a step-wise analysis to understand the observed deviations between the data and fits for Eq. 4. To check the role of the geometry and size of the particles an analysis with computational fluid dynamics is performed. The role of shrinkage is investigated by using the concepts of volume reduction [6] and the effect of fractal change of thickness [14]. RuizLopez and Garcia-Alvarado [13] relate the diffusivity of water in the product matrix to moisture content. In line with their observations a moisture dependent diffusion coefficient is evaluated in this work.

\section{Materials and Methods}

\subsection{Yam species and sample preparation}

Yam tubers, Dioscoreaceae rotundata cultivar Dente, were precisely cut into discs of $10 \mathrm{~mm}$ thickness and subsequently the discs were further cut into square dimensions of $30 \mathrm{~mm}$ by $30 \mathrm{~mm}$. The dimensions of the samples were measured using digital calipers (model: 01407A, NEIKO, USA) of $0.02 \mathrm{~mm}$ accuracy.

\subsection{Shrinkage and moisture measurements}

In separate experiments on shrinkage, ten fresh yam cuts $(3 \times 3 \times 1 \mathrm{~cm})$ were placed in the drying chamber and dried at 30, 40 and $50^{\circ} \mathrm{C}$. Before and after drying for 2, 4, 6, and 15 hours for all temperatures, plus 19, 42 and 72 hours for 50,40 and $30^{\circ} \mathrm{C}$, respectively and, 5 samples 
81 (replicates) were randomly selected from the drying chamber. For each sample cubicle, the side

82 thickness $\left(S_{T}\right)$ and side lengths $\left(S_{L}\right)$ were determined with the digital calipers at the four sides of

83 the sample, while the center thickness $\left(C_{T}\right)$ was measured three times within the neighborhood of

84 the center of the sample. The average values each of the $S_{T}, \mathrm{~S}_{\mathrm{L}}$ and $\mathrm{S}_{\mathrm{T}}$ ere calculated. After the size

85 measurements the corresponding moisture content of the samples were determined.

According to [14] the relative sample thickness and sample volume are related to each

87 other by an exponential relation with fractal dimensional exponent $(z)$ as shown in Eq. 5:

$$
\frac{L_{i}}{L_{0}}=\left[\frac{V_{i}}{V_{0}}\right]^{1 / z}
$$

88 With $V_{0}$ and $L_{0}$ respectively the initial sample volume $\left(\mathrm{mm}^{3}\right)$ and thickness $(\mathrm{mm}), V_{i}$ and $L_{i}$ the

89 volume and thickness of the sample at the sampling moments during drying. The thickness of the

90 sample is the average value from the four measured side thicknesses $\left(S_{T}\right)$ and the center thickness

$91 \quad\left(C_{T}\right):$

$$
L_{i}=\left[\frac{4 S_{T}+C_{T}}{5}\right]
$$

92 The circular deformation from the sides to the center at the top and bottom surface of the sample

93 is considered as a parabolic form. With symmetrical surfaces, the actual volume of the product is

94 then the volume of a square product $V_{s q r}$ minus the volume of the parabolic indentions $V_{\text {par }}$ :

$$
V_{i}=V_{s q r}-2 V_{p a r}=S_{L}^{2} S_{T}-2\left(0.5 \pi r^{2} h\right)
$$

95 With $r=\frac{S_{L}}{2}$ the radius of parabola basis and $h=\frac{S_{T}-C_{T}}{2}$ the height of the parabola.

\section{2.3. CFD- calculations}

98 In COMSOL two geometries of product cubicles $(3 \times 3 \times 1 \mathrm{~cm})$ were defined and Ficks diffusion 99 equation was applied to these geometries. Simulations were performed with a diffusion coefficient 
of $2.5 \times 10^{-10} \mathrm{~m}^{2} / \mathrm{s}$. The initial condition for water content throughout the geometry was set to 1.0

$101 \mathrm{~kg} / \mathrm{m}^{3}$ and at the boundaries of the geometry at $0.0 \mathrm{~kg} / \mathrm{m}^{3}$. Drying in the first geometry corresponds

102 to an infinite slab by blocking water transport through the side surfaces which results in water

103 transport through only the top and bottom surface. The second geometry concerned the actual

104 drying behavior by moisture transport through all surfaces. The results were evaluated by fitting

105 Eq. 4 to the simulated moisture content as a function of time.

106

107

\subsection{Drying procedure and equipment}

The dryer system was made up of a fan, heating element and drying chamber. Ambient air at a speed of $2.6 \mathrm{~m} / \mathrm{s}$ reaches the heating element by a fan (accuracy $\pm 0.05 \mathrm{~m} / \mathrm{s}$ ) through a controlled valve. The temperatures of the heated air and in the chamber were measured with K-type

111 thermocouples (accuracy $\pm 0.1^{\circ} \mathrm{C}$ ). The relative humidity of the inlet air to the dryer was 112 determined by a relative humidity sensor of accuracy $\pm 0.2 \% \mathrm{RH}$. The inlet air enters the dryer at 113 the bottom side and leaves at the top side (See Figure 1).

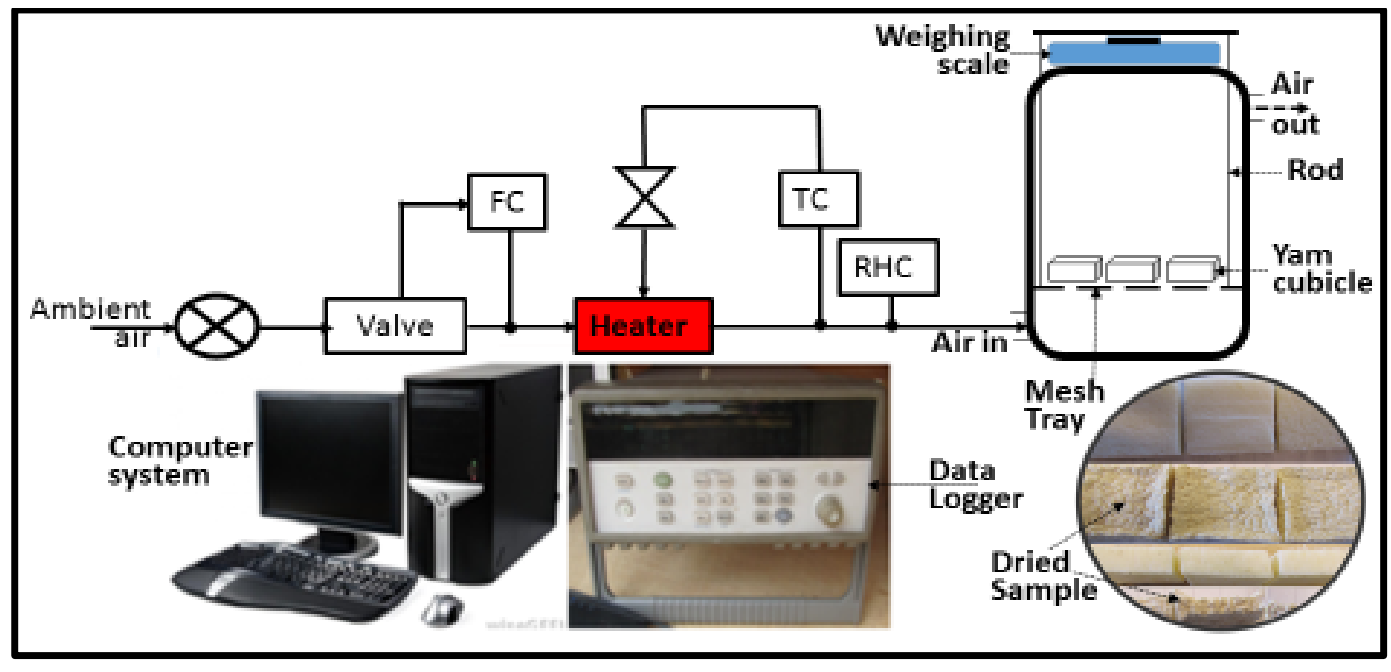

Figure 1 Schematic overview of the drying equipment with flow control (Fl $\mathrm{Ctl})$ and temperature

116 control ( $\mathrm{T} \mathrm{Ctl}$ ), processor and data logger 
118 The air flow and air temperature were kept constant through PID controllers. At steady state of

119 temperature and air speed, yam cuts $(3 \times 3 \times 1 \mathrm{~cm})$ weighing between $170-180 \mathrm{~g}$ were carefully placed

120 on a wire mesh tray in the drying chamber (Figure. 1). The wire mesh tray is connected to a

121 weighing scale (Mettler Toledo, PM250, Switzerland) to automatically read the changes in weight

122 during drying. An Agilent data logger (model: 34970A, USA) logs and stores the drying air 123 temperatures, air speed, relative humidity and changes in the sample weight by using a Labview

124 interface. All data were recorded within intervals of 2 seconds each and repeated for drying air 125 temperatures of 30,40 and $50^{\circ} \mathrm{C}$.

126

\section{$127 \quad 2.5$. Statistical analysis of data}

128 Nonlinear regression in Matlab was used for parameter estimation of the models to the 129 experimental data. The extent of variation between experimental data and model was determined 130 with the statistical performance indicators:

Standard error:

$$
S E=\sqrt{\frac{\sum_{i=1}^{N_{e}}(\text { Residuals })^{2}}{N_{e}-N_{p}}}
$$

Percent average relative deviation:

$$
\begin{aligned}
\operatorname{PRD}(\%) & =\frac{100}{N_{e}} \sum_{i=1}^{N_{e}}\left(\frac{\mid \text { Residuals } \mid}{X}\right) \\
M S e & =\frac{\sum_{i=1}^{N_{e}}(\text { Residuals })^{2}}{N_{e}}
\end{aligned}
$$

131 Where the residuals are the differences between the observed and predicted data. and $X$ is the

132 observed moisture content value. In general, a better fit is obtained with more parameters, but the 133 improvement must be worth-while. Akaike's Information Criterion (AIC) is especially suitable 134 for comparing models with a different number of parameters. The criterion is defined by 


$$
A I C=2 N_{p}+N_{e} \ln (V(\widehat{\mathbf{p}}))
$$

135 based on the likelihood function, but ignoring the constant term $-N_{e} \ln \left(N_{e}\right)-N_{e} \ln (2 \pi)-N_{e}$.

136 The model with the lowest AIC is preferred. Here $V(\widehat{\boldsymbol{p}})$ is the sum of squares errors, $N_{p}$ is the 137 number of parameters of a particular model, and $N_{e}$ is the number of experimental data points. All 138 data were processed and evaluated using the Matlab software.

\section{Results and Discussion}

140 3.1. Shrinkage

141 Table 1 shows the mean dimensions of the yam cubicles and its corresponding moisture content in 142 time. Shrinkage is highest in the center of the cubicle and is temperature dependent. The percentage 143 shrinkage is between $44-64 \%$ in the center with highest shrinkage recorded at $50^{\circ} \mathrm{C}$ From the data 144 in Table 1 first the thickness and volume were calculated according Eqns. 6 and 7 and next the 145 results were transformed to the relative thickness $\left(L_{c}=L_{i} / L_{0}\right)$ and relative volume $\left(V_{c}=V_{i} / V_{0}\right)$ 146 by dividing with the initial values at start of the experiment. These results are given in Table 2. 
Table 1 Measured dimensions of yam cubicles and moisture content for drying at 30,40 and $50^{\circ} \mathrm{C}$

\begin{tabular}{|c|c|c|c|c|c|c|c|c|c|c|c|c|}
\hline \multirow{2}{*}{$\begin{array}{l}\text { Time } \\
\text { (h) }\end{array}$} & \multicolumn{4}{|c|}{$30{ }^{\circ} \mathrm{C}$} & \multicolumn{4}{|c|}{$40^{\circ} \mathrm{C}$} & \multicolumn{4}{|c|}{$50^{\circ} \mathrm{C}$} \\
\hline & $S_{L}(\mathrm{~cm})$ & $S_{T}(\mathrm{~cm})$ & $C_{T}(\mathrm{~cm})$ & $X(d b)$ & $S_{L}(\mathrm{~cm})$ & $S_{T}(\mathrm{~cm})$ & $C_{T}(\mathrm{~cm})$ & $X(d b)$ & $S_{L}(\mathrm{~cm})$ & $S_{T}(\mathrm{~cm})$ & $C_{T}(\mathrm{~cm})$ & $\mathrm{X}(\mathrm{db})$ \\
\hline 0 & 3.00 & 1.00 & 1.00 & 2.330 & 3.00 & 1.00 & 1.00 & 2.330 & 3.00 & 1.00 & 1.00 & 2.330 \\
\hline 2 & $\begin{array}{c}2.93 \\
(0.019) \\
\end{array}$ & $\begin{array}{c}0.91 \\
(0.037)\end{array}$ & $\begin{array}{c}0.92 \\
(0.032) \\
\end{array}$ & 1.758 & $\begin{array}{c}2.84 \\
(0.030) \\
\end{array}$ & $\begin{array}{c}0.90 \\
(0.021) \\
\end{array}$ & $\begin{array}{c}0.89 \\
(0.022) \\
\end{array}$ & 1.390 & $\begin{array}{c}2.83 \\
(0.073) \\
\end{array}$ & $\begin{array}{c}0.86 \\
(0.017) \\
\end{array}$ & $\begin{array}{c}0.85 \\
(0.012) \\
\end{array}$ & 1.12 \\
\hline 4 & $\begin{array}{c}2.85 \\
(0.065)\end{array}$ & $\begin{array}{c}0.88 \\
(0.032)\end{array}$ & $\begin{array}{c}0.87 \\
(0.043)\end{array}$ & 1.589 & $\begin{array}{c}2.76 \\
(0.04)\end{array}$ & $\begin{array}{c}0.83 \\
(0.024)\end{array}$ & $\begin{array}{c}0.78 \\
(0.035)\end{array}$ & 1.104 & $\begin{array}{c}2.7 \\
(0.053)\end{array}$ & $\begin{array}{c}0.8 \\
(0.024)\end{array}$ & $\begin{array}{c}0.64 \\
(0.011)\end{array}$ & 0.77 \\
\hline 6 & $\begin{array}{c}2.78 \\
(0.049) \\
\end{array}$ & $\begin{array}{c}0.87 \\
(0.032) \\
\end{array}$ & $\begin{array}{c}0.79 \\
(0.045) \\
\end{array}$ & 1.132 & $\begin{array}{c}2.69 \\
(0.047) \\
\end{array}$ & $\begin{array}{c}0.79 \\
(0.029) \\
\end{array}$ & $\begin{array}{c}0.72 \\
(0.031) \\
\end{array}$ & 1.055 & $\begin{array}{c}2.6 \\
(0.026) \\
\end{array}$ & $\begin{array}{c}0.79 \\
(0.039) \\
\end{array}$ & $\begin{array}{c}0.56 \\
(0.045) \\
\end{array}$ & 0.52 \\
\hline 15 & $\begin{array}{c}2.74 \\
(0.046)\end{array}$ & $\begin{array}{c}0.84 \\
(0.031)\end{array}$ & $\begin{array}{c}0.62 \\
(0.027)\end{array}$ & 0.625 & $\begin{array}{c}2.61 \\
(0.057)\end{array}$ & $\begin{array}{c}0.74 \\
(0.029)\end{array}$ & $\begin{array}{c}0.56 \\
(0.024)\end{array}$ & 0.400 & $\begin{array}{c}2.5 \\
(0.042)\end{array}$ & $\begin{array}{c}0.7 \\
(0.020)\end{array}$ & $\begin{array}{c}0.48 \\
(0.028)\end{array}$ & 0.254 \\
\hline 19 & - & - & - & - & - & - & - & - & $\begin{array}{c}2.48 \\
(0.036)\end{array}$ & $\begin{array}{c}0.68 \\
(0.019)\end{array}$ & $\begin{array}{c}0.36 \\
(0.032)\end{array}$ & 0.045 \\
\hline 47 & - & - & - & - & $\begin{array}{c}2.58 \\
(0.029) \\
\end{array}$ & $\begin{array}{c}0.70 \\
(0.02)\end{array}$ & $\begin{array}{c}0.50 \\
(0.035)\end{array}$ & 0.140 & - & - & - & - \\
\hline 72 & $\begin{array}{c}2.71 \\
(0.025)\end{array}$ & $\begin{array}{c}0.83 \\
(0.026) \\
\end{array}$ & $\begin{array}{c}0.56 \\
(0.025) \\
\end{array}$ & 0.170 & - & - & - & - & - & - & - & - \\
\hline$\%$ Shr & 10 & 17 & 44 & - & 14 & 30 & 50 & - & 17 & 32 & 64 & - \\
\hline$S d v_{\text {ave }}$ & 0.0408 & 0.0316 & 0.0344 & & 0.0406 & 0.0246 & 0.029 & & 0.046 & 0.0238 & 0.0272 & \\
\hline $\begin{array}{c}\text { Stdev } \\
\text { (Stdev) }\end{array}$ & 0.0187 & 0.00391 & 0.00915 & & 0.01180 & 0.00427 & 0.00660 & & 0.01799 & 0.00887 & 0.01509 & \\
\hline
\end{tabular}


153 Table 2 Relative volume $\left(V_{c}\right)$ and thickness $\left(L_{c}\right)$ derived from the product dimensions (Table 1) 154 and product moisture content $(X(t))$ during drying at temperatures ranging between $30-50{ }^{\circ} \mathrm{C}$

\begin{tabular}{llll}
\hline Moisture content $X(\mathrm{~kg} / \mathrm{kg})$ & Relative thickness $\mathrm{L}_{\mathrm{c}}(-)$ & Relative volume $\mathrm{V}_{\mathrm{c}}(-)$ \\
\hline $30^{\circ} \mathrm{C}$ & & & \\
\hline & 2.33 & 1.00 & 1.00 \\
& 1.76 & 0.91 & 0.87 \\
1.59 & 0.88 & 0.79 \\
& 1.13 & 0.85 & 0.72 \\
& 0.63 & 0.80 & 0.63 \\
& 0.17 & 0.78 & 0.59 \\
\hline $40^{\circ} \mathrm{C}$ & & & \\
\hline & 2.33 & 1.00 & 1.00 \\
& 1.39 & 0.90 & 0.80 \\
& 1.10 & 0.82 & 0.69 \\
& 0.66 & 0.78 & 0.61 \\
& 0.40 & 0.70 & 0.51 \\
& 0.14 & 0.66 & 0.46 \\
\hline $50{ }^{\circ} \mathrm{C}$ & & & \\
\hline & 2.33 & 1.00 & 1.00 \\
& 1.12 & 0.86 & 0.76 \\
0.77 & 0.77 & 0.60 \\
& 0.52 & 0.74 & 0.52 \\
0.25 & 0.66 & 0.43 \\
0.05 & 0.62 & 0.38 \\
\hline
\end{tabular}

155

156 Linear regression of relative thickness $\left(L_{c}\right)$ against moisture content $(X)$ at temperatures 30,40 and $15750{ }^{\circ} \mathrm{C}$ respectively gave the combined linear equations as:

$$
L c(X, T)=(0.0033 \mathrm{~T}+0.0105) \mathrm{X}+0.8870-0.0054 \mathrm{~T}
$$

158

159 Equation 5 relates the relative thickness $\left(L_{c}\right)$ and relative volume $\left(V_{c}\right)$ through the fractal coefficient 160 (z). Figure 2 presents the double logarithmic plot of relative thickness and volume for all data 161 from Table 2, which results in average fractal factor, $z=1.98$. This value is in the upper range 162 of the values found by [14] and $(\mathrm{z}=1.4-1.8)$ and indicates a relative strong contribution of the 163 sample thickness to the volume (See Figure 2). 


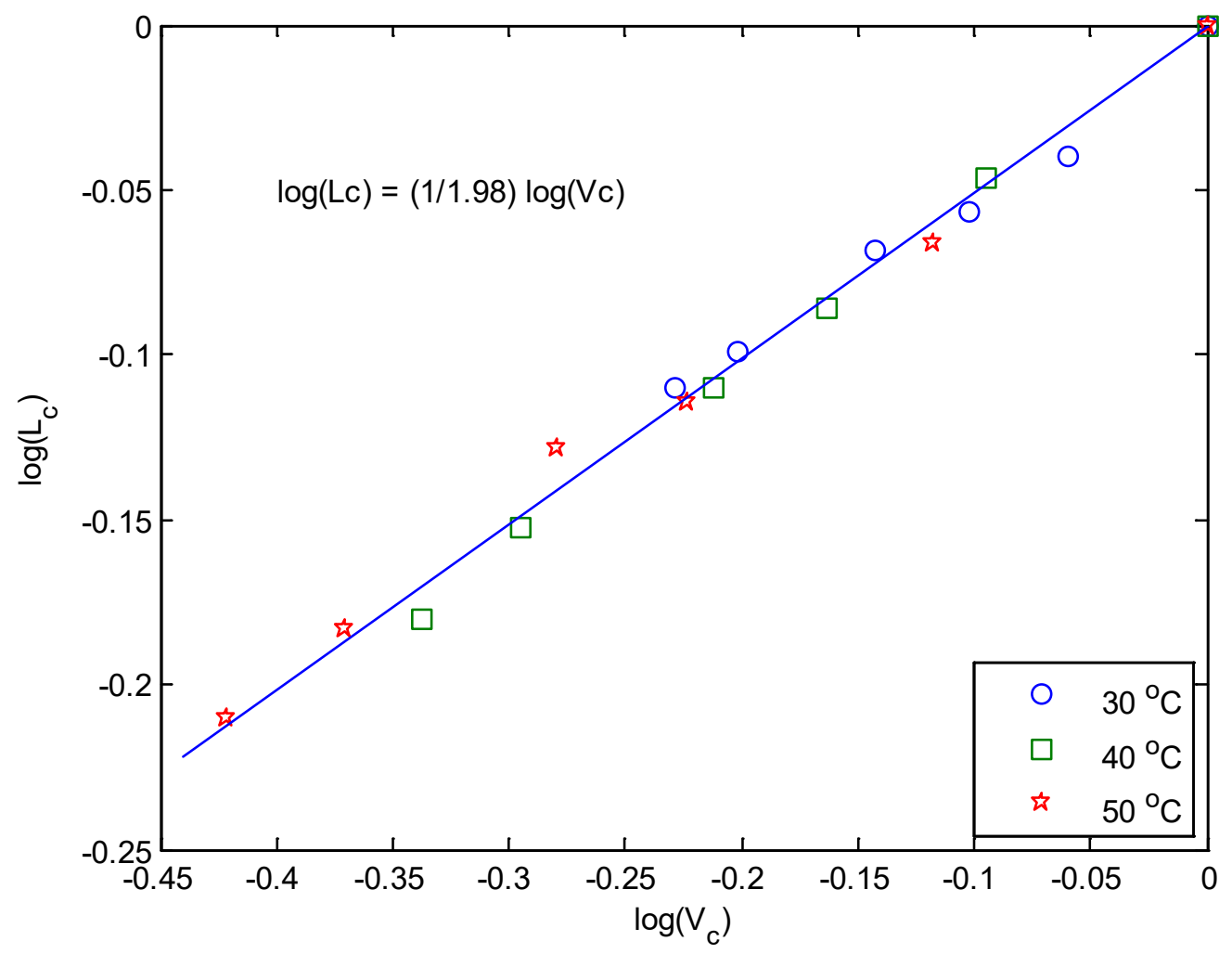

164

165

166

167

168 The yam cubicle dimensional reduction during drying represented by the relative volume from

169 Table 2 at temperatures $30-50^{\circ} \mathrm{C}$ showed non-linear relationships with moisture content $(X)$

170 Regression analysis of $\log \left(V_{c}\right)$ as a function of $X-X o$ is given as:

$$
\log \left(V_{c}\right)=S X-S X_{0}
$$

171 Where $S$ is the slope, $X_{0}$ is the initial moisture content, $X$ is the moisture content in time, both

172 given as $\mathrm{kg}$ water/ $\mathrm{kg}$ dry matter. The combination gives

$$
\log (V c)=(0.0038 \mathrm{~T}-0.0012) X-0.0065 \mathrm{~T}+0.0738
$$

173 The expression for the final relative thickness is then:

$$
\frac{L}{L_{0}}=L_{c}=10^{\frac{[(0.0038 \mathrm{~T}-0.0012) X-(0.0065 \mathrm{~T}+0.0738)]}{Z}}
$$


174 Both equation 12 and 15 give an expression for the relative thickness as a function of moisture

175 content and temperature. The difference between both equations arises from the applied procedure

176 to link the relative thickness to the moisture content. Equation 12 is based on direct regression

177 between thickness and moisture content, while equation 15 is based on regression between product

178 volume and moisture content.

179

180 3.2. Drying and drying rate curves

181 Figure 3 (top) shows the drying curves of the observed data of yam cubicles at temperatures of 30 ,

18240 and $50^{\circ} \mathrm{C}$. The figure shows the well-known trends for drying curves, with a decreasing 183 moisture ratio over time and shorter drying times for higher temperatures. From the raw data the 184 drying rate was derived and expressed as a function of the moisture ratio (Figure 3 (bottom)). 185 Figure 3 (bottom) shows that the drying rate increases with moisture ratio and with steeper slope 186 for higher temperatures. The plots show two main phases of rates which can, at first sight, be 187 approximated by linear functions as: 1) a linear function for the range $0-0.5$ and a linear function 188 for the range above 0.5 . Jannot et al. [15] reported of 3 phases for banana. In the next part these 189 phases section are analyzed by Crank’s approximation for Fick’s second law. 

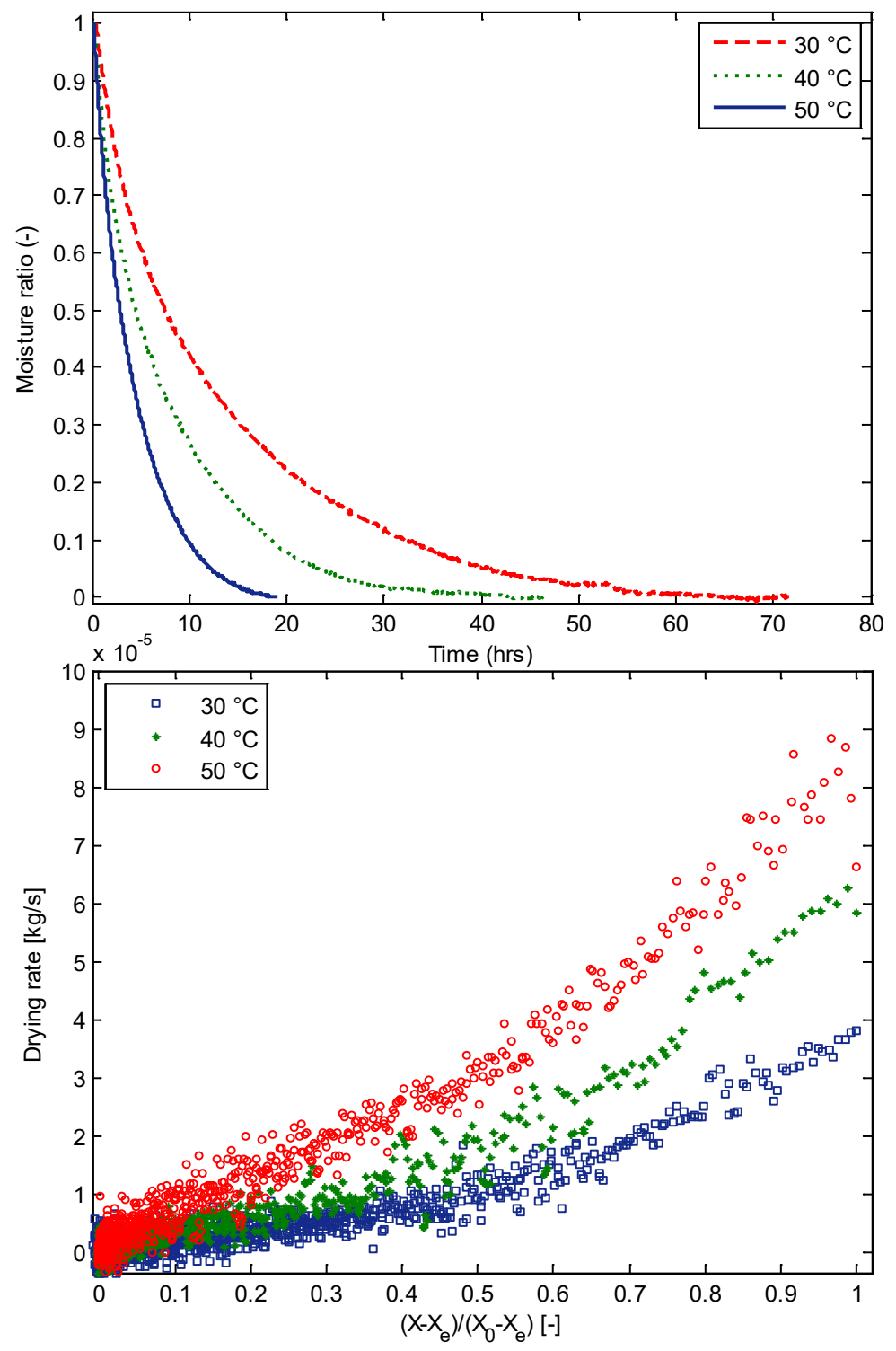

190

191

192 (bottom) of yam at different temperatures

\subsection{CFD-results}

Figure 4 represents the distribution for the moisture ratio in product samples with moisture transport through all product edges at 20000 and 50000 seconds. The distribution, with a gradual

197 decrease of moisture towards the edges of the product, is a characteristic example for diffusional 

there is only a gradient towards top and bottom of the sample.
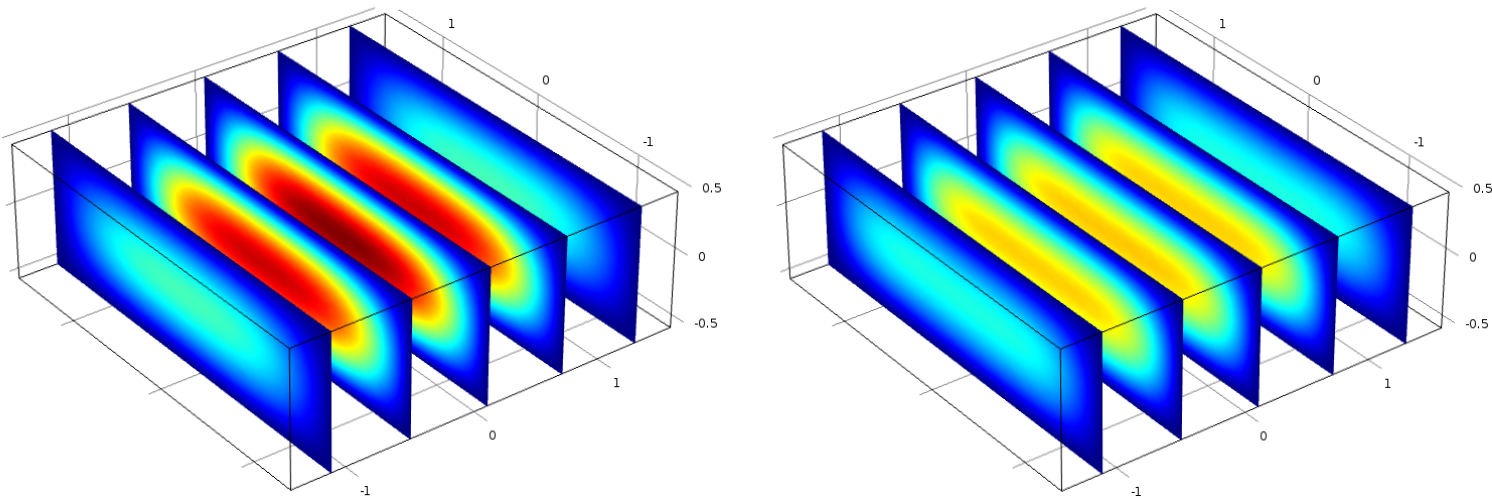

Figure 4 Profile of moisture ratio in the product samples with transport through all side planes at 20000 and 50000 seconds of drying.

Like in Figure 3, CFD generated data of the drying rate for the two geometries are plotted against the moisture ratio in Figure 5 (top: transport through only bottom and top and satisfying the properties of an infinite slab, bottom: moisture transport through all sides). Comparison of the results shows that the drying rate in the second geometry is above that of the first geometry, which is evident due to the larger product surface available for drying. Applying the three term model (Eq. 3) to fit the drying curve $(X(t)$ as a function of time resulted in the dashed lines in both graphs. Overall, the drying rate from the three term model is in both cases very close to the data, the main difference is in the region of the high moisture ratio. The performance in the high moisture region could be slightly improved by adding more terms. The estimated diffusion coefficient for the first geometry corresponds to that used in the simulations to generate the data. For the second geometry 
214 the estimated diffusion coefficient is higher due to the larger drying rates that result from the extra

215 moisture transferring surfaces. These results show that, with a higher effective diffusion

216 coefficient, Crank's approximation can also be applied for the considered particles with moisture

217 transport through the side surfaces. Moreover, the different phases in the drying rate in Figure 3

218 are not result of the rather small dimensions of the particles used in the experiments.
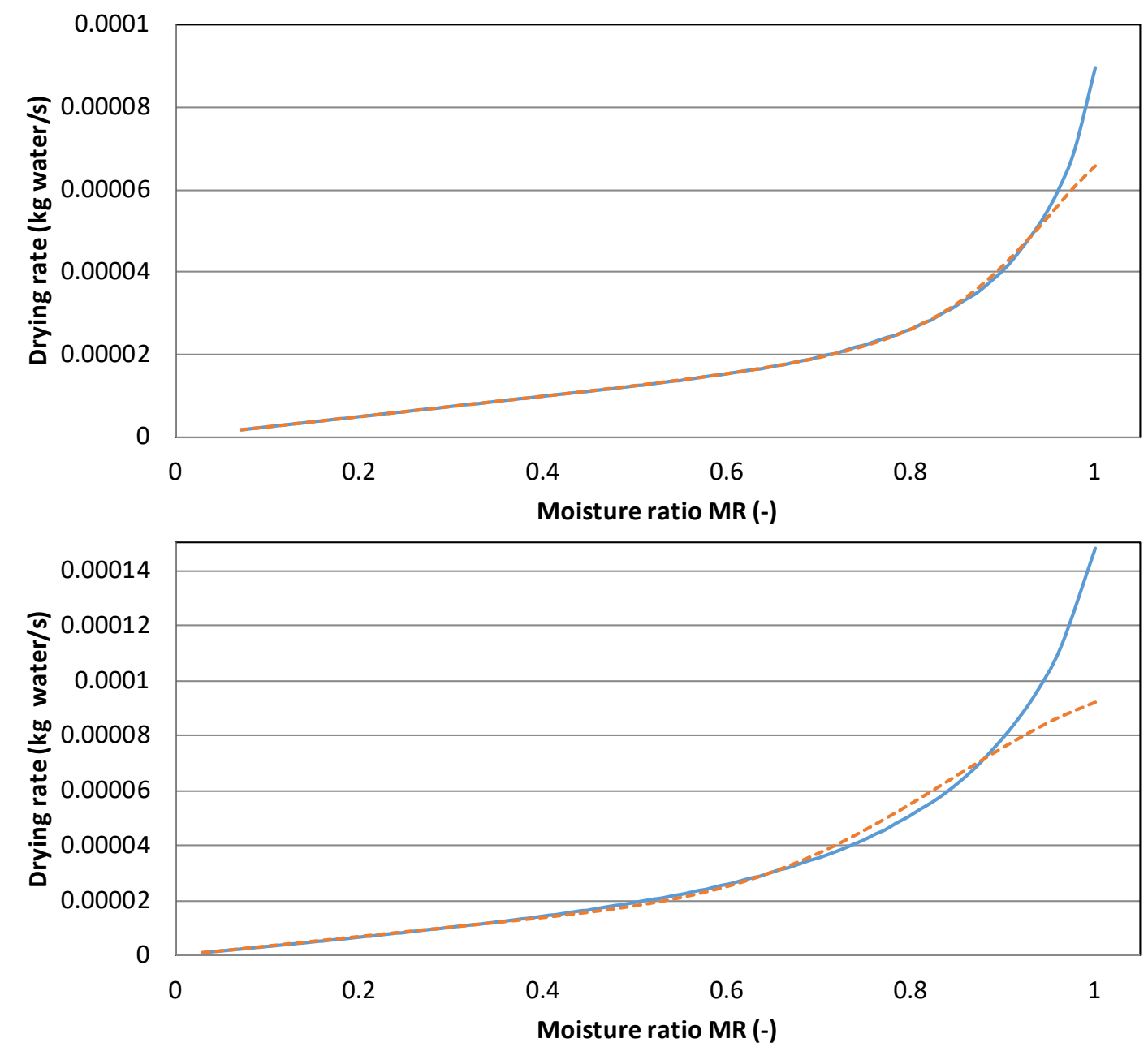

219

220 Figure 5. Comparing CFD generated data for a geometry with moisture transport through the top 221 and bottom surface (top), and a geometry with moisture transport through all sides (bottom).

222 Drawn line CFD data, dashed line approximation with the Crank's approximation with three terms. 


\subsection{Fitting drying curves to data}

225 The form of the drying rate curves for the data generated by CFD and the measured data given in 226 Figure 3 (bottom) have a large similarity and therefore the measured drying curves were fitted with 227 the Eq. 4 with 2 terms. The noise in the measured data was too high for a statistical meaningful 228 application of 3 terms (Eq. 3). To compensate partly for the effects of higher terms, the coefficient 229 of the second term in the right hand side of Eqn. (4) is considered as a parameter (Eq. 16).

$$
\text { Non-linear } \quad M R(t)=\mathrm{a} \exp \left(-\frac{\pi^{2} D(X)}{L(X)^{2}} t\right)+p \exp \left(-\frac{9 \pi^{2} D(X)}{L(X)^{2}} t\right)
$$

232 At first, Eq. 16 is fitted to the data with fixed values for the diffusion coefficient $D$ and sample

233 thickness $L$. Figure 6 shows measured and model curves of the non-linear approximation for the

234 diffusion equation (where $\mathrm{a}=\frac{8}{\pi^{2}}$ ). The obtained parameters and the statistics of the fit are given 235 in Table 2.

236 Figure 6 (top) represents moisture ratio as a function of time while the bottom figure represents 237 the drying rate as a function of moisture ratio at constant slab thickness and diffusion coefficient. 238 The figures show systematic errors in the models, while the drying rate curves reflect a drastic 239 deviation of the models from the observed data. However, it is able to produce the two phases as 240 observed in Figure 4 (bottom). The deviation of the drying rate curve (Figure 6, bottom) can 241 possibly be a result from 1) product shrinkage, 2) a moisture dependent diffusion coefficient, or 3) 242 a combination of these two. 

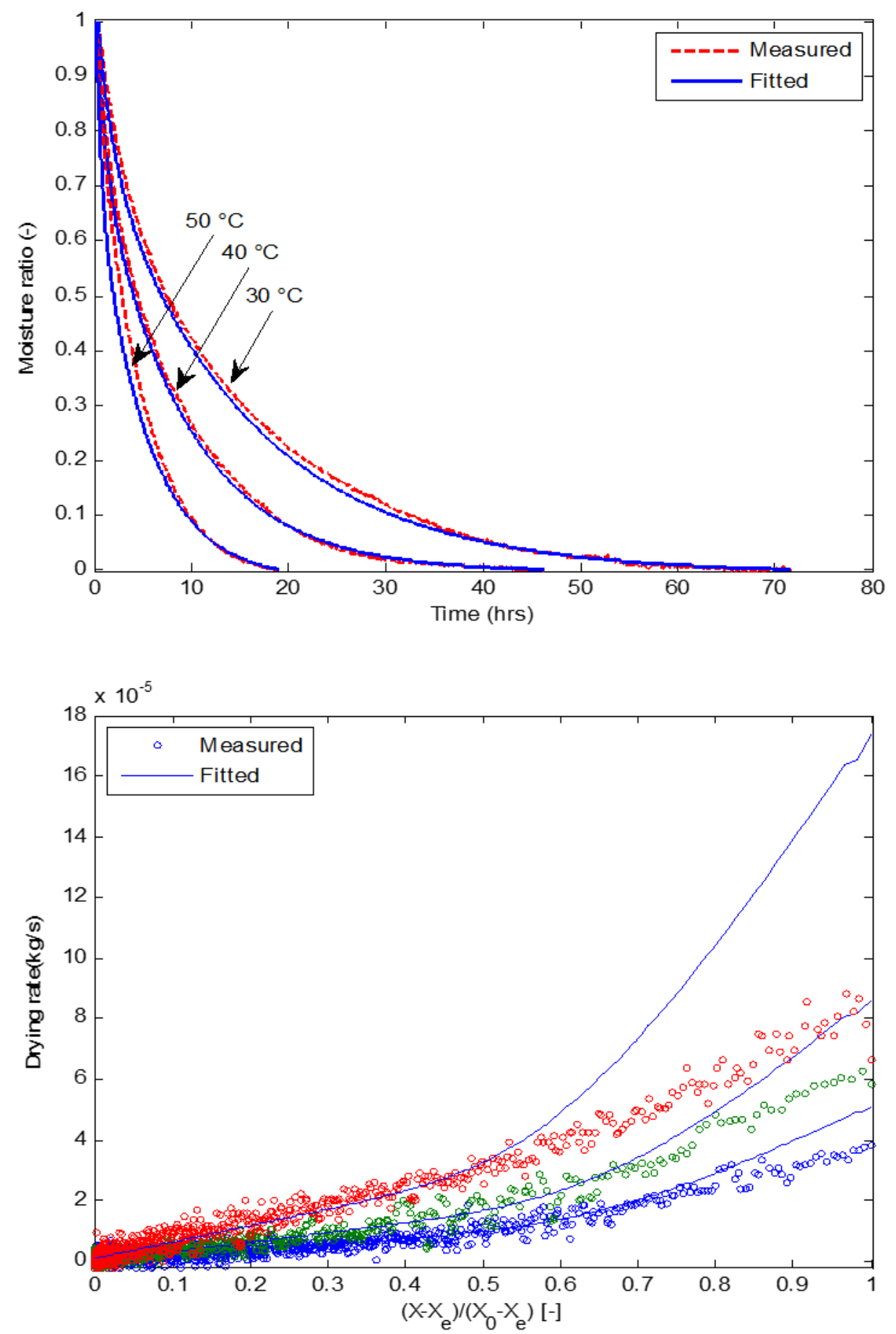

Fig 6. Results for the two term diffusion equation approximation. Moisture ratio as a function of

246 time (top), drying rate as a function of moisture ratio (bottom) at constant slab thickness and 247 diffusion coefficient. 
249 Table 2 Estimated parameters with coefficient of variation in brackets (\%) and statistical results

250 for two-term at constant sample thickness and diffusion coefficient.

\begin{tabular}{lclll}
\hline & Temperature ${ }^{\circ} \mathrm{C}$ & 30 & 40 & 50 \\
\hline & $D \times 10^{-10} \mathrm{~m}^{2} / \mathrm{s}$ & $1.833(0.22)$ & $3.143(0.28)$ & $5.472(0.93)$ \\
& $p$ & $0.301(1.59)$ & $0.300(2.013)$ & $0.434(5.26)$ \\
& $M S e \times 10^{-4}$ & 0.577 & 0.553 & 0.694 \\
$\begin{array}{l}\text { Two term equation at constant } \\
\text { slab thickness and diffusion } \\
\text { coefficient }\end{array}$ & $\mathrm{SE}$ & 0.007 & 0.007 & 0.0263 \\
& $\mathrm{PRD}$ & 2.987 & 3.306 & 15.707 \\
& $\mathrm{AIC}$ & -3336.810 & -2559.481 & -508.501 \\
& $R^{2}$ & 0.999 & 0.999 & 0.998 \\
\hline
\end{tabular}

251

252 Because of the systematic deviations in both the drying curve and drying rate curve the effect of

253 the dependency of $L$ and $D$ on $X$, is studied by considering four options. The results are given in

$254 \quad$ Figure 7 and Table 3.

255

256 Option one: left graphs in Figure 7, concern a variable slab thickness, linearly related to the

257 moisture content $\left(L(X)=c_{1} X(t)+c_{2}\right.$, and based on Eq. (12), and a constant diffusion coefficient

258 (D). The fits for the moisture ratio over time in Figure 7a and the drying rate in Figure $7 \mathrm{~b}$ deviate

259 significantly from the data, especially the drying curve.

260

261 Option two: Figure 7c,d, middle graphs, gives the results for an effective diffusion coefficient, 262 linearly related to the moisture content according to $D(X)=D_{0}+b X(t)$, in combination with a 263 constant slab thickness. Compared to option 1, the drying curve with moisture ratio over time fits 264 better to the data, which is also reflected by a lower mean squared error and standard error etc. 
265 (see Table 3). Moreover, the drying rate model fits better to the data. However, the coefficient $b$ 266 in the expression $D(X)=D_{0}+b X(t)$ is negative. This implies that the diffusion coefficient 267 decreases with moisture content. In other words diffusive moisture transport becomes easier 268 towards the end of drying, which is contradictory to the general experience from the literature [15].

Option three: Both sample thickness and diffusion coefficient are linearly related to the moisture 271 content as presented in the previous options. The results are presented in Figure 7e,f (right graphs).

272 In these graphs, the model results for the drying and drying rate curves are the closest to the data.

273 The coefficient $b$ in the expression $D(X)=D_{0}+b X(t)$ is now positive which indicates a 274 decreasing diffusion coefficient with decreasing moisture content. This result corresponds to a 275 decline of water mobility during drying which corresponds to the general experience and which is 276 amongst others explained by the free volume theory [16]. Compared with option 2, option 3 277 confirms the assertion by [17] that the diffusion coefficient varies during drying together with 278 thickness. However, this option fails to predict well the observed data at high moisture content due 279 to the accuracy level of the predictability of the initial relative length $(\mathrm{Lc}=1.0)$.

281 Option four: Instead of Eq. 12, the fractal thickness of the sample as a function of moisture content 282 from Eq. 15 is applied in combination of the effective diffusion coefficient, linearly related to the 283 moisture content (see Figure 8). The parameters and fitting results are summarized in Table 3. 284 The drying and the drying rate curves show similar fit with that of the third option but now with 285 good prediction of the high initial moisture content. 
287 Statistically, for the various temperatures, options 2, 3 and 4 are close and give the lowest MSe 288 (10 fold or more lower), SE, PRD, AIC and higher $\mathrm{R}^{2}$ compared to options 1 . However option 2 is 289 rejected for the fact that the coefficient of $b$ is negative while option 4 is preferred over option 3 290 due to the good prediction of the high moisture region.

291 Actually, options three and four are very close and differ only in the way the thickness of the 292 sample is related to the product moisture content. In option three, the relation was direct derived 293 from the thickness data, while in option four the expression was based on the product volume. The 294 last approach proved to be a more suitable method when dealing with non-infinite slabs and gives 295 a better data smoothing result. 

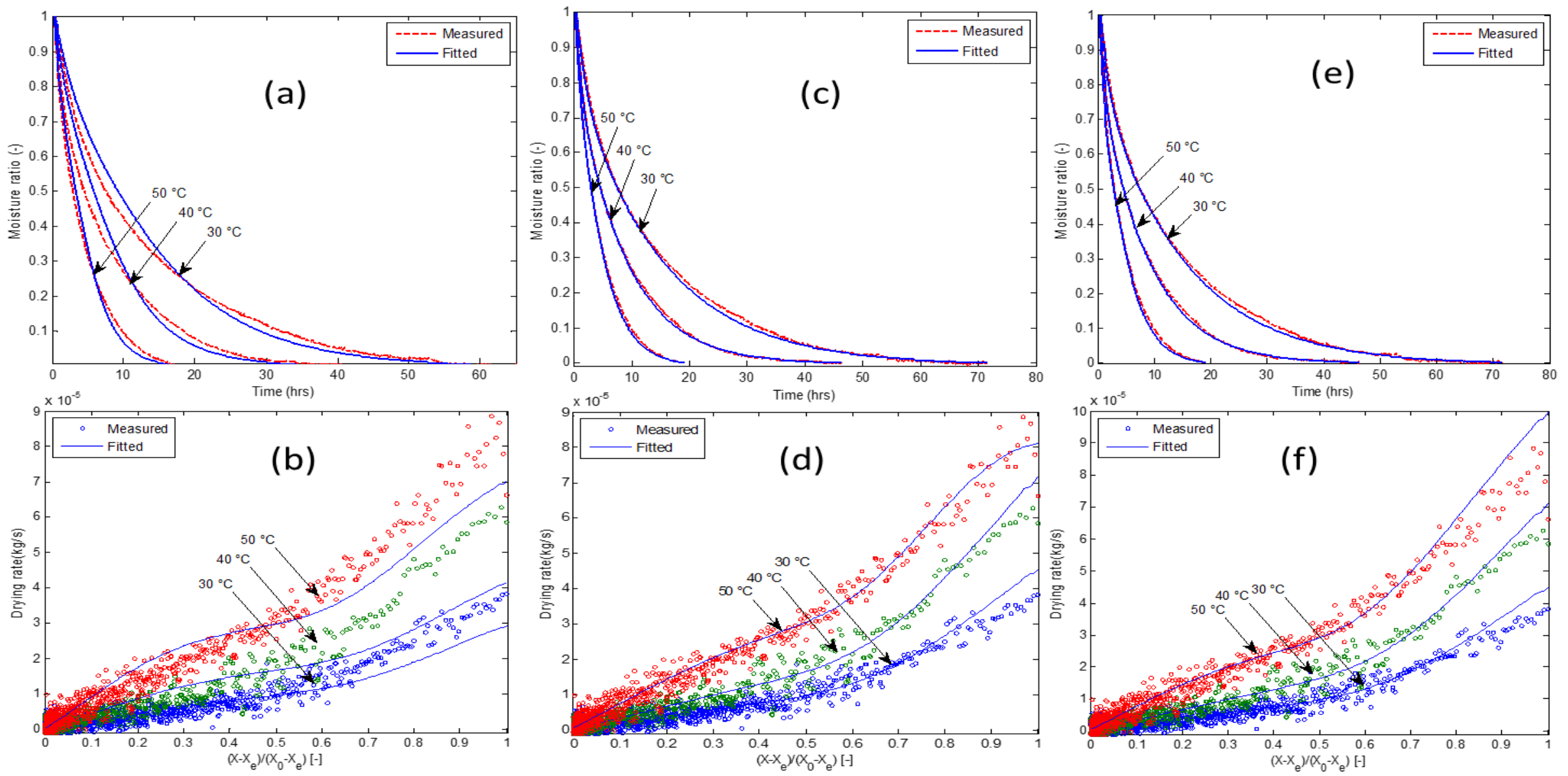

298 Figure 7 Results for the two term diffusion equation approximation (Eq. 16). Shrinkage as linear function of moisture content and 299 constant diffusion coefficient (a,b). No shrinkage and diffusion coefficient as a linear function of moisture content (c,d). Combined 300 effect of shrinkage and diffusion coefficient both linearly related with moisture content (e,f). 


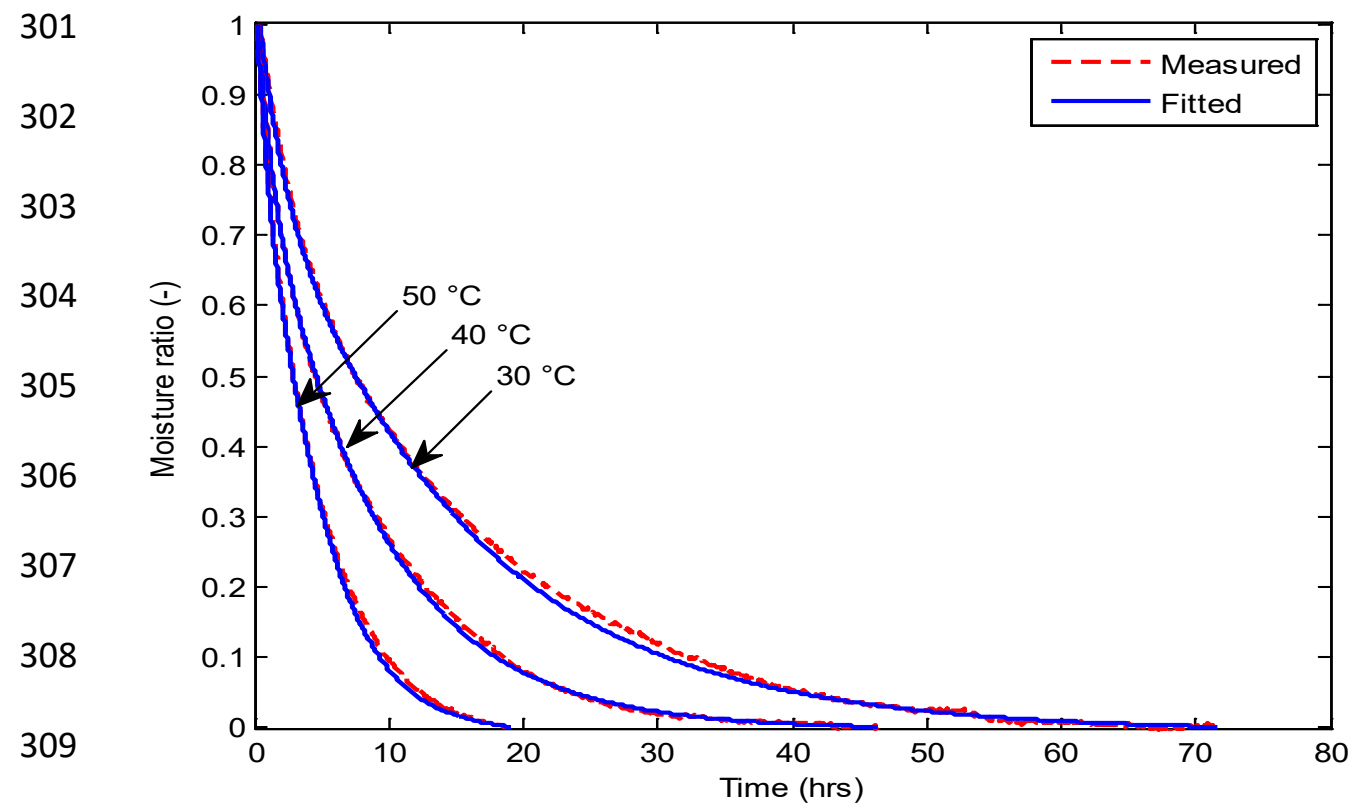

310

311

312

313

314

315

316

317

318

319

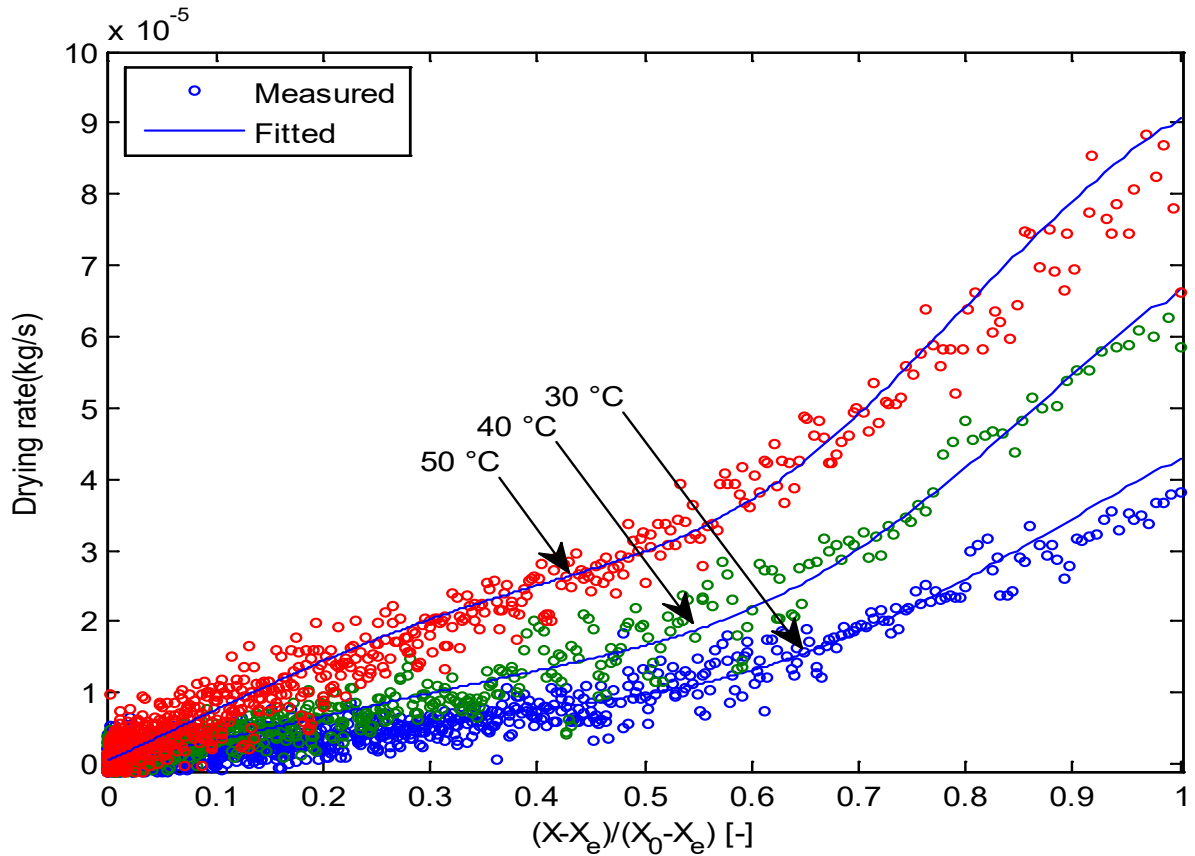

320 Figure 8 Results for the two term diffusion equation approximation (Eq. 16). Fractal thickness

321 shrinkage (Eq.13) as a linear function of moisture content and diffusion coefficient linearly elated

322 to moisture content. Top: Moisture as a function of time; Bottom: Drying rate as function of 323 moisture content. 
Table 2. Estimated parameters with coefficient of variation in brackets (\%) and statistical results for the four model options.

\begin{tabular}{|c|c|c|c|c|}
\hline & Temperature ${ }^{\circ} \mathrm{C}$ & 30 & 40 & 50 \\
\hline \multirow{7}{*}{$\begin{array}{l}\text { Moisture content related slab } \\
\text { thickness } \\
L(X)=c_{1} X(t)+c_{2} \text {, Eq } 12 \text {. }\end{array}$} & $D \times 10^{-10} \mathrm{~m}^{2} / \mathrm{s}$ & $1.117(0.55)$ & $1.850(0.76)$ & $2.914(0.55)$ \\
\hline & $p$ & $0.189(4.30)$ & $0.161(6.87)$ & $0.210(3.72)$ \\
\hline & $M S e \times 10^{-4}$ & 3.297 & 4.691 & 3.459 \\
\hline & $\mathrm{SE}$ & 0.018 & 0.022 & 0.018 \\
\hline & PRD & 3.224 & 4.186 & 5.326 \\
\hline & AIC & -1102.039 & -780.727 & -982.535 \\
\hline & $R^{2}$ & 0.999 & 0.998 & 0.999 \\
\hline \multirow{8}{*}{$\begin{array}{l}\text { Moisture content } \\
\text { diffusion coefficient } \\
D(X)=D_{0}+b X(t)\end{array}$} & $D_{o} \times 10^{-10} \mathrm{~m}^{2} / \mathrm{s}$ & $1.896(0.40)$ & $3.308(0.36)$ & $6.481(0.38)$ \\
\hline & $b \times 10^{-11}$ & $-0.899(-9.72)$ & $-2.461(-5.86)$ & $-15.069(-1.87)$ \\
\hline & $p$ & $0.276(1.72)$ & $0.261(1.64)$ & $0.245(1.93)$ \\
\hline & $M S e \times 10^{-4}$ & 0.447 & 0.224 & 0.404 \\
\hline & $\mathrm{SE}$ & 0.007 & 0.005 & 0.006 \\
\hline & PRD & 2.552 & 2.153 & 5.847 \\
\hline & AIC & -3669.424 & -3251.979 & -2443.452 \\
\hline & $R^{2}$ & 0.999 & 0.999 & 0.999 \\
\hline \multirow{8}{*}{$\begin{array}{l}\text { Combination of moisture } \\
\text { related diffusion coefficient } \\
\text { and slab thickness } \\
L(X)=c_{1} X(t)+c_{2} \text {, Eq } 12 \\
D(X)=D_{0}+b X(t)\end{array}$} & $D_{o} \times 10^{-10} \mathrm{~m}^{2} / \mathrm{s}$ & $0.999(0.47)$ & $1.494(0.45)$ & $2.567(0.45)$ \\
\hline & $b \times 10^{-11}$ & $2.574(2.48)$ & $5.280(1.81)$ & $5.203(3.04)$ \\
\hline & $p$ & $0.272(1.63)$ & $0.257(1.54)$ & $0.279(1.49)$ \\
\hline & $M S e \times 10^{-4}$ & 0.436 & 0.231 & 0.2 .97 \\
\hline & $\mathrm{SE}$ & 0.007 & 0.005 & 0.005 \\
\hline & PRD & 2.501 & 2.052 & 4.446 \\
\hline & AIC & -3693.266 & -3283.395 & -2652.928 \\
\hline & $R^{2}$ & 0.999 & 0.999 & 0.999 \\
\hline \multirow{8}{*}{$\begin{array}{l}\text { Combination of moisture } \\
\text { related diffusion coefficient } \\
\text { and fractal slab thickness } \\
L(X) \text { : Eq } 15 \text {. } \\
D(X)=D_{0}+b X(t)\end{array}$} & $D_{o} \times 10^{-10} \mathrm{~m}^{2} / \mathrm{s}$ & $1.008(0.48)$ & $1.506(0.48)$ & $2.607(0.45)$ \\
\hline & $b \times 10^{-11}$ & $2.490(2.63)$ & $4.953(2.08)$ & $4.250(3.80)$ \\
\hline & $p$ & 0.264 (1.69) & $0.246(1.71)$ & $0.259(1.57)$ \\
\hline & $M S e \times 10^{-4}$ & 0.458 & 0.274 & 0.316 \\
\hline & $\mathrm{SE}$ & 0.007 & 0.005 & 0.006 \\
\hline & PRD & 2.593 & 2.271 & 5.044 \\
\hline & AIC & -3631.399 & -3142.735 & -2611.829 \\
\hline & & 0.999 & 0.999 & 0.999 \\
\hline
\end{tabular}




\subsection{Discussion}

Mulet [12] emphasizes the role of shrinkage and varying diffusivity for the interpretation of drying curves. Ruiz-Lopez and Garcia-Alvarado[13] reported that a better estimation of effective diffusion coefficient can be achieved when both shrinkage and diffusivity as functions of moisture are factored in such models. In this work an additional analysis was made by examining curves of the drying rate as a function of moisture ratio. These curves show that the two-term approximation of the diffusion equation (equation 4) fit for the yam cubicles. The drying rate showed different stages during drying. Hassini et al. [5] modelled the stages by determining different values for the diffusion coefficient in each stage. In contrast to the work [5] in the current work the variation in diffusive transport is modelled by the two mechanisms: shrinkage and moisture dependent diffusion behavior. The moisture dependent diffusion behavior is attributed to the mobility of water in the product matrix, which is governed by the cell structure in yam and different water adsorption properties in mono and multilayers. Verma et al. [18] mentioned also starch gelatinization as possible reason for the variable diffusion behavior for product for temperatures beyond $65^{\circ} \mathrm{C}$, but this level of temperature was not reached in this work.

The models with moisture dependent diffusion have one additional parameter $(b)$. According to the lower AIC (Table 3) for those models, the addition of this extra parameter is justified. The two equations (12) and (15) do not differ much. However, in the interest of accurate prediction of the high moisture region preference is given to inclusion of the fractal shrinkage in the model.

The analytical expression for the diffusion in a slab as given by Crank explains the two apparent stages in the drying rate as a function of moisture ratio. These stages appear in a similar 
way for large infinite slabs as the smaller cubicles. The trend in these phases is strongly supported by the introduction of a sample moisture dependent thickness and diffusion coefficient in the model.

The mathematical form of the two-term approximation for Fick's diffusion equation as given in Eq. 16 corresponds to models used in semi-empirical expressions for the drying rate [18,19,20]. In those models the exponential terms are only estimated parameters. It is common practice to reject or to modify the mentioned models if the model does not adequately fit to the data. Examples of modifications are discussed in the review of [21]. Instead of modifying or seeking for another model, in this work the parameters were linked to moisture dependent diffusion behavior and shrinkage, which leads more to the fundamentals of moisture transport.

This work was focused on the mass transport by diffusion. From the dynamics for heat transfer a time constant around 30 seconds was derived. Therefore, the role of variations in temperature on the very slow mechanism of moisture transport can be neglected. The product samples remained close to the dryer inlet air temperature. Product quality degradation, like vitamin $\mathrm{C}$ and color were not the focus of this work. Vitamin $\mathrm{C}$ degradation which can already occur at the applied drying temperatures in the high moisture content region [22] needs attention in further investigation.

\section{Conclusion}

Crank's analytical solution of Fick's diffusion equation for slabs has been used to describe the drying behavior of yam (Dioscoreaceae rotundata cultivar Dente) in terms of moisture dependency of shrinkage and diffusivity. The analytical expression for the diffusion in a slab is 
also valid for the smaller cubicles, but results in a higher effective diffusion coefficient, and shows two stages in the drying rate as a function of moisture ratio.

The comparative study of moisture dependent shrinkage and moisture dependent diffusivity justifies the interdependence of diffusivity and shrinkage due to water loss during drying. This study shows that this behavior for yam is best explained by a combination of fractal moisture dependent shrinkage and moisture dependent diffusion. The moisture dependent diffusion behavior can be attributed to mobility of water from the food matrix due to different moisture content in the multilayer and monolayer regimes. The results from this study challenges to investigate the drying behavior of other food products.

\section{Nomenclature}

Symbols used for drying models

$$
\begin{array}{cl}
a, b, c_{1}, c_{2}, n & \text { Constants } \\
C_{T}, C_{T 0} & \text { Centre thickness of sample during drying and initial centre thickness }(\mathrm{cm}) \\
D & \text { Effective diffusion coefficient }\left(\mathrm{m}^{2} / \mathrm{s}\right) \\
D_{0} & \text { Reference value for effective diffusion coefficient }\left(\mathrm{m}^{2} / \mathrm{s}\right) \\
h & \text { Height of parabolic inclination at top and bottom of sample (m) } \\
L, L(X) & \begin{array}{l}
\text { Thickness of yam samples and thickness as a function of moisture content } \\
(\mathrm{m})
\end{array} \\
L_{i}, L_{0} & \text { Measured sample thickness during drying, and initial sample thickness (m) } \\
L_{c} & \text { Relative thickness (-) } \\
M R(t) & \text { Moisture ratio (-) } \\
p & \text { Second term pre-exponential coefficient of the two term diffusion equation }
\end{array}
$$




$\begin{array}{cl}r & \text { Radius of parabolic inclination at top and bottom of sample (m) } \\ S_{T}, S_{T 0} & \text { Side thickness of sample and initial side thickness (cm) } \\ S_{L}, S_{L 0} & \text { Side length of a sample and initial side length (cm) } \\ t & \text { Time (s) } \\ V_{i}, V_{0} & \text { Measured sample volume during drying, and initial sample volume }\left(\mathrm{m}^{3}\right) \\ V_{c} & \text { Relative volume (-) } \\ V_{s q r}, V_{p a r} & \text { Volume of rectangular part of sample, volume of parabolic inclination at top } \\ x & \text { and bottom of sample (m) } \\ X(t) & \text { Position in the product compared to the center (m) } \\ X_{0}, X e & \text { Initial and equilibrium moisture content }(\mathrm{kg} \text { water } / \mathrm{kg} \text { dry matter) } \\ Z & \text { Fractal coefficient (-) }\end{array}$

Symbols used for statistics

$\begin{array}{cl}\text { AIC } & \text { Aikaike information criterion } \\ M S e & \text { Mean squared error } \\ N_{e} & \text { Number of data points } \\ N_{p} & \text { Number of parameters } \\ \text { PRD } & \text { Percentage relative deviation } \\ \text { Residuals } & \text { Not yet given } \\ S E & \text { Standard error } \\ V(\hat{p}) & \text { Sum of squared errors } \\ \bar{X} & \text { Mean value }\end{array}$

\section{Acknowledgement}


This project was funded by the Wageningen University and Research Centre (WUR), The Netherlands and Kwame Nkrumah University of Science and Technology (KNUST), Kumasi, Ghana. The authors are grateful for this financial and consumables contribution. 


\section{References}

[1] Fioreze, R., Morini, B. Yam (Discorea sp) Drying with different cuts and temperatures: experimental and simulated results. Ciencia Technology, Alimentos. 2000, 20, 262-266.

[2] Torres, R., Montes, E.J., Andrade, R.D., Perez, O.A., Toscano, H. Drying kinetics of two yam (Dioscoreaceae alata) varieties. Dyna. 2011, 79(171), 175-182.

[3] Yadollahinia, A. Jahangiri, M. (2009) Shrinkage of potato slice during drying, Journal of Food Engineering 94, 52-58.

[4] Al-Muhtaseb, A.H., McMinn, W.A.M., Magee, T.R.A., 2004. Shrinkage, density and porosity variations during the convective drying of potato starch gel. In: 14th International Drying Symposium (IDS), São Paulo, Brazil, vol. C, pp. 1604-1611. Eds. M.A. Silva, Campinas State University, Brazil.

[5] Hassini, L., Azzouz, S. Peczalski, R. Belghith, A. Estimation of potato moisture diffusivity from convective drying kinetics with correction for shrinkage, Journal of Food Engineering $2007,79,47-56$

[6] Sjöholm, I. and Gekas, V. Apple Shrinkage upon Drying, Journal of Food Engineering. 1995, $25,123-130$.

[7] Crank, J. The Mathematics of Diffusion. 1975. Oxford University Press. Oxford.

[8] Ah-Hen, K.,Zambra, C.E.,Aguëro, J.E.,Vega-Gálvez, A.,Lemus-Mondaca,R., Moisture diffusivity coefficient and convective drying modelling of murta (Ugni molinae Turcz): Influence of temperature and vacuum on drying kinetics. Food and Bioprocess Technology (2013) 6(4) 919-930. 
[9] Ben Haj Said, L., Najjaa, H., Farhat, A., Neffati, M., \& Bellagha, S. (2015). Thin layer convective air drying of wild edible plant (Allium roseum) leaves: experimental kinetics, modeling and quality. Journal of Food Science and Technology, 52(6), 3739-3749.

[10] Chayjan, R.A., Salari K, Barikloo H. Modeling moisture diffusivity, activation energy and specific energy consumption of squash seeds in a semi fluidized and fluidized bed drying Acta Sci Pol Technol Aliment. 2012, 11(2):131-48.

[11] Asiah, N., Djaeni, M., Hii, C.L. Moisture transport mechanism and drying kinetic of fresh harvested red onions bulbs under dehumidified air. International Journal of Food Engineering, 2017. DOI:10.1515/ijfe-2016-0401

[12] Mulet, A. Drying modelling and water diffusivity in carrots and potatoes. Journal of Food Engineering, 1994, 22, 329-348.

[13] Ruiz-Lopez. I.I., Garcia-Alvarado M.A. Analytical solution for food-drying kinetics considering shrinkage and variable diffusivity. Journal of Food Engineering. 2007,79: 208216.

[14] Gekas, V.; Lamberg, I. Determination of Diffusion Coefficients in Volume-Changing Systems - Application in the Case of Potato Drying Journal of Food Engineering. 1991, 14, 317-326.

[15] Jannot, Y., Talla, A., Nganhou, J., Puiggali, J.R. Modeling of banana convective drying characteristic curve (DCC) method. Drying Technology. 2004, 22, 1949-1968.

[16] Jin X., Sman, R.G.M.van der, Boxtel A.J.B. van. Evaluation of the Free Volume Theory to predict moisture transport and quality changes during broccoli drying. Drying Technology. 2011, 29(16),1963-1971. 
[17] Tütüncü, M.A., Labuza, T. P. Effect of Geometry on the Effective Moisture Transfer Diffusion Coefficient, Journal of Food Engineering. 1996, 30, 433-447.

[18] Verma L.R., Bucklin R.A., Endan J.B., Wratten F.T. Effect of drying air parameters on rice drying models. Transaction of the ASAE, 1985, 28(1), 296-301.

[19] Henderson, S.M. Progress in developing the thin layer drying equation. Transactions of the ASAE 1974,17,1167-1172.

[20] Sharaf-Eldeen, Y.I., Blaisdell, P.N., Hamdy , M.Y. A model for corn drying. Transactions of the ASAE 1980,23,1261-1271.

[21] Erbay, Z., Icier, F. A review of thin layer drying of foods: Theory, modelling, and experimental results. Critical Reviews in Food Science and Nutrition. 2010, 50:5,441-464. 